\title{
SOCIO-DEMOGRAPHIC AND CLINICAL CHARACTERISTICS OF TURKISH WORKERS WITH PNEUMOCONIOSIS
}

\author{
Hilal Altınöz', Cengiz Çelikkalkan², Gönül Dinç Horasan², Fatih Hamşioğlu², Nalan Cengiz², Hikmet Orbay² \\ ${ }^{1}$ Pulmonary Division, Faculty of Medicine, Acibadem University, Istanbul, Turkey \\ ${ }^{2}$ Istanbul Occupational Disease Hospital, Istanbul, Turkey \\ ${ }^{3}$ Public Health Division, Faculty of Medicine, Celal Bayar University, Manisa, Turkey
}

\section{SUMMARY}

Aim: Pneumoconiosis is caused by inhaling dust. The aim of the study was to analyze 208 cases of workers' pneumoconiosis.

Method: Patients' files were used for the descriptive study.

Results: All patients were male aged $38.82 \pm 13$ years. The most important symptom was breathlessness. Patients were denim sandblasters $(50.5 \%)$, dental technicians (12\%), coal miners (6.7\%), and others. The mean exposure time before pneumoconiosis occurred was shorter in denim sandblasters and teflon kitchenware producers compared to other occupations ( $5.4 \pm 4.2$ and $4.5 \pm 3.3$ years, respectively). Profusion $(76.5 \%)$ was more than $1 / 2$ by the International Labour Organization (ILO) classification. Pulmonary function tests were negatively correlated with profusion.

Conclusion: Denim sandblasters and teflon kitchenware producers have less exposure time before pneumoconiosis occurs and they become symptomatic earlier. As Turkish workers suffering from pneumoconiosis are younger, measures to prevent pneumoconiosis must be the priority of the healthcare authorities.

Key words: pneumoconiosis, denim sandblasters, Turkish workers, dental technicians

Address for correspondence: H. Altınöz, Pulmonary Division, Faculty of Medicine, Acibadem University, Narcity A6/49 Maltepe, Istanbul, Turkey. E-mail: hilalaltinoz@yahoo.com

http://dx.doi.org/10.21101/cejph.a4694

\section{INTRODUCTION}

Pneumoconiosis is a lung disease caused by inhaling dust (1). In Turkey it is a very common (the third common occupational health problem according to the Social Security Statistics) and preventable disease deteriorating the quality of life, with a higher mortality (according to the International Labour Organization (ILO) $21 \%$ of occupation-related deaths is due to chronic pulmonary diseases). Because the notification system for pneumoconiosis is generally inadequate, the occupational health statistical data regarding pneumoconiosis are thus insufficient in Turkey. Therefore, the socioeconomic and clinical features of the diagnosed cases are not well known. This is a very important issue when attempting to plan the health system response to pneumoconiosis. The largest data source in Turkey is available in three occupational disease hospitals' patient files. The aim of the study was to determine socio-demographic, clinical and radiological characteristics of the patients as well as the risky jobs in our region, to describe the people at risk of pneumoconiosis, and in the long run to make the policy makers to acknowledge the results of the study in order to control pneumoconiosis in Turkey.

\section{MATERIALS AND METHODS}

The study setting - Istanbul Occupational Disease Hospital is one of the three occupational disease hospitals in Turkey. Its catchment area is the northwest part of Turkey and Izmir (both highly industrialized areas of Turkey). The participants recruited for this descriptive study were all pneumoconiosis patients diagnosed from January 1, 2008 to December 31, $2010(\mathrm{~N}=208)$. Data was obtained from the patients' files in January 2011. Data collection was conducted by trained researchers (four physicians) who filled in a form. Demographic variables included age, sex, social security type, and smoking habit. Work related variables included occupation, exposed material and exposure time. The ILO classification of each case was done during hospitalization by an ILO reader and two other pulmonary physicians. The ILO classification, according to the revised 2011 edition, was used to classify the profusion and nodule existence (2). Clinical variables included pulmonary function tests (PFT) (FEV1 in percentage, FVC in percentage, FEV1/FVC and DLCO (in Kco in percentage). Both tests were performed according to the American Thoracic Society guidelines. The most important symptom of the patient at admission was recorded. 


\section{Statistical Analysis}

Data were presented as means \pm SDs or median (25th-75th) for numerical variables, and percentages for categorical variables. Chi square test and Mann-Whitney U test were used with SPSS 16.0 (SPSS, Inc., Chicago, USA).

Table 1. Smoking status $(N=208)$

\begin{tabular}{|l|c|c|}
\hline Smoking status & $\mathbf{n}$ & $\%$ \\
\hline Nonsmoker/ex-smoker & 148 & 71.4 \\
\hline Smoker & 26 & 12.5 \\
\hline Unknown & 34 & 16.1 \\
\hline
\end{tabular}

Table 2. The most important symptoms of the patients $(N=208)$

\begin{tabular}{|l|c|c|}
\hline Symptom & $\mathbf{n}$ & $\%$ \\
\hline Breathlessness & 94 & 45.2 \\
\hline Cough & 44 & 21.2 \\
\hline Chest pain & 22 & 10.7 \\
\hline Others & 19 & 9.1 \\
\hline No symptom & 19 & 9.1 \\
\hline Unknown & 10 & 4.7 \\
\hline
\end{tabular}

Table 3. Occupations and exposure times $(N=208)$

\begin{tabular}{|l|c|c|}
\hline Occupations & $\mathbf{n}(\%)$ & $\begin{array}{c}\text { Occupation } \\
\text { exposure time } \\
\text { (year) }\end{array}$ \\
\hline Denim sandblaster & $105(50.5)$ & $5.4 \pm 4.2$ \\
\hline Dental technician & $25(12.0)$ & $17.6 \pm 8.5$ \\
\hline Coal miner & $14(6.7)$ & $25.1 \pm 8.7$ \\
\hline Casting & $10(4.8)$ & $12.8 \pm 9.7$ \\
\hline Sandblasting for teflon pot & $8(3.8)$ & $4.5 \pm 3.2$ \\
\hline Ceramic worker & $8(3.8)$ & $13.7 \pm 10.5$ \\
\hline Sandblasting for other reasons & $7(3.4)$ & $9.4 \pm 10.9$ \\
\hline Welder & $5(2.4)$ & $13.2 \pm 8.2$ \\
\hline Quartz worker & $5(2.4)$ & $5.8 \pm 5.3$ \\
\hline Tunnel worker & $5(2.4)$ & $23.6 \pm 4$ \\
\hline Raw glass worker & $4(1.9)$ & $12.2 \pm 7.4$ \\
\hline Lathe worker & $2(1.0)$ & $16.5 \pm 9.2$ \\
\hline Other & $10(4.8)$ & $15 \pm 8.6$ \\
\hline Total & $208(100.0)$ & $9.9 \pm 9$ \\
\hline
\end{tabular}

Table 4. Exposure materials

\begin{tabular}{|l|c|}
\hline Exposure material & $\%$ \\
\hline Silicium & 86.4 \\
\hline Coal dust & 5.8 \\
\hline Iron dust & 3.4 \\
\hline Iron dust and silicium & 3.4 \\
\hline Metal dust & 0.5 \\
\hline Metal dust and silicium & 0.5 \\
\hline
\end{tabular}

Table 5. ILO classification ( $N=208)$

\begin{tabular}{|l|c|c|}
\hline Profusion & $\mathbf{n}$ & $\%$ \\
\hline $1 / 0,1 / 1,1 / 2$ & 35 & 16.8 \\
\hline $2 / 0,2 / 1,2 / 2,2 / 3$ & 80 & 38.5 \\
\hline $3 / 0,3 / 1,3 / 2,3 / 3,3 /+$ & 79 & 38.0 \\
\hline Unknown & 14 & 6.7 \\
\hline Total & 208 & 100.0 \\
\hline
\end{tabular}

Table 6. ILO classification $(N=208)$

\begin{tabular}{|l|c|c|}
\hline Opacity & $\mathbf{n}$ & $\%$ \\
\hline None & 134 & 64.4 \\
\hline A & 37 & 17.8 \\
\hline B & 28 & 13.5 \\
\hline Unknown & 9 & 4.3 \\
\hline
\end{tabular}

Table 7. Pulmonary function test (PFT) results (percentage)

\begin{tabular}{|l|c|c|c|c|}
\hline Pulmonary function & Min & Max & Mean & $\mathbf{\pm S D}$ \\
\hline FEV1\% & 21 & 115 & 67.27 & 23.31 \\
\hline FVC\% & 23 & 126 & 73.78 & 20.86 \\
\hline FEV1/FVC & 45 & 129 & 85.16 & 16.02 \\
\hline DLCO & 4 & 224 & 102.74 & 28.10 \\
\hline
\end{tabular}

\section{RESULTS}

The results are shown in Tables. All of the patients were male aged $38.82 \pm 13$ years. The smoking status of the patients is shown in Table 1 . The most important symptoms were breathlessness, cough and chest pain. Symptomless were $9.1 \%$ of patients (Table 2). Investigated workers were denim sandblasters $(50.5 \%)$,

Table 8. PFT results versus classification $(N=208)$

\begin{tabular}{|l|l|c|c|c|}
\hline Profusion & & FVC $\%$ & FEV1\% & FEV1/FVC \\
\hline \multirow{2}{*}{$1 / 0,1 / 1,1 / 2$} & Mean & $89.67 \pm 17.7$ & $85.91 \pm 19.4$ & $88.24 \pm 15$ \\
\cline { 2 - 5 } & $\mathrm{n}$ & 33 & 33 & 33 \\
\hline \multirow{2}{*}{$2 / 0,2 / 1,2 / 2,2 / 3$} & Mean & $75.53 \pm 18$ & $67.15 \pm 2$ & $83.01 \pm 14$ \\
\cline { 2 - 5 } & $\mathrm{n}$ & 79 & 79 & 79 \\
\hline \multirow{2}{*}{$3 / 0,3 / 1,3 / 2,3 / 3,3 /+$} & Mean & $67.28 \pm 2$ & $61.06 \pm 2$ & $85.85 \pm 1$ \\
\cline { 2 - 5 } & $\mathrm{n}$ & 79 & 79 & 78 \\
\hline \multirow{2}{*}{ Total } & Mean & $74.56 \pm 1$ & $67.87 \pm 2$ & $85.08 \pm 1$ \\
\cline { 2 - 5 } & $\mathrm{n}$ & 191 & 191 & 190 \\
\hline
\end{tabular}


dental technicians $(12 \%)$, coal miners $(6.7 \%)$, casting $(4.8 \%)$, teflon kitchenware producers $(3.8 \%)$, ceramic workers $(3.8 \%)$, and others $(4.8 \%)$ (Table 3$)$. The mean exposure time before the occurrence of pneumoconiosis symptoms was significantly shorter in denim sandblasters and teflon kitchenware producers compared to the other workers $(5.4 \pm 4.2$ and $4.5 \pm 3.3$ years, respectively) (Table 3). Silica was the most often detected hazardous material $(86.5 \%)$ (Table 4). Profusion (76.5\%) was more than $1 / 2$ by the ILO classification (Table 5). The ratio of A or B nodules was $31.3 \%$ (Table 6 ). The pulmonary function test results of the patients are shown in Table 7 . The period between the occurrence of symptoms and diagnosis did not change by the profusion. The pulmonary function tests were negatively correlated with the profusion (Table 8).

\section{DISCUSSION}

Silicosis is a fibrogenic disease causing lung fibrosis. It causes disability and work loss. The patients' files were provided by one of the three occupational diseases hospitals in Turkey. The catchment area of the hospital is the Marmara region and Izmir where the majority of industry is located. So we can generalize the results of this study to the results of Turkey.

As we look at the socio-demographic characteristics we see that the workers are generally falling into the young age group. They are all male because in these types of professions women do not work. Nearly half of our patients are denim sandblasters. Denim sandblasting has started in Turkey since the beginning of 1990 . It has been forbidden in European countries and the companies moved to our country. Workers in nearly all denim sandblasting workplaces were not covered by social security and no regular physical examinations were provided during the employment. The work was mostly performed in places lacking air conditioning or workplace hygiene. Other sandblasting works except for dental technicians have better work conditions as there are some hygiene regulations.

The most important symptom observed is breathlessness but proportion of our patients with this symptom is lower than stated by other researchers (3). We suppose that some workers without any symptom may also undergo medical examination to see whether they have an occupational disease for compensation claims. An important ratio of the cases (2/3) include denim sandblasters and dental technicians. All of the workers belong to lower social classes. A good number of these workers have severe profusion. When we compared our results with the literature data, our cases fell into higher ILO categories (4). Young people having diffuse chronic lung disease have low pulmonary function tests. As shown in Table 8 as the profusion increases the respiratory functionality decreases. The quality of life of patients is severely affected. This is an urgent social issue waiting for solution. We want to point out that nearly 4 of 10 workers (especially the younger ones) have become affected during their first five years of exposure. Although the regulations on sandblasting in Turkey came into force in 2009 , there is still a need to make the control system work more efficiently.

It may be concluded that denim sandblasting is the main cause of pneumoconiosis in Turkey and therefore new regulations have been accepted by the government, it has been strictly forbidden since 2009 and denim sandblasting pneumoconiosis patients get the advantage of having compensation since 2010. In contrast, in China where $70 \%$ of people suffering from pneumoconiosis live, pneumoconiosis in coal workers is still number one (5). We know that the exposure time in a workday is very important but we were not able to obtain such data from the files. Also no air dust measurement was recorded in the files. We plan to rearrange our patient files so that the physician establishing the history of disease can easily remember the important facts about dust concentration. Seventy-one percent of our patients were not smoking and $13 \%$ of them were smokers, however, in $16 \%$ of examined files this information was missing. The nonsmoking cases are not known to be exsmoker or never smoker. As smoking is a very important confounder for the lung diseases we have to prevent this type of mistake by rearranging the file forms and reminding the form-fillers. Generally, each paper in the literature discusses only one type of occupation causing pneumoconiosis. To our knowledge this is the first study concerning almost all occupations causing the disease.

Since there are many cases of pneumoconiosis among dental technicians in Turkey, some regulations concerning dental technicians were adopted in $2011(6,7)$.

We conclude that denim sandblasters and teflon kitchenware producers may suffer from pneumoconiosis earlier than workers in other risky jobs. As our pneumoconiosis workers are mostly younger, regulations preventing pneumoconiosis must be the priority of the healthcare authorities.

\section{Conflict of Interests}

None declared

\section{REFERENCES}

1. Shellito J. Occupational, inhalational, environmental disease. In: Ali J, Summer WR, Levitzky MG, editors. Pulmonary pathophysiology: a clinical approach. 3rd ed. New York: McGraw-Hill Medical; 2010. p. $149-65$.

2. International Labour Organization. Guidelines for the use of the ILO International Classification of Radiographs of Pneumoconioses. Occupational Safety and Health Series No. 22 (Rev. 2011). Geneva: International Labour Organization; 2011.

3. Akgun M, Araz O, Akkurt I, Eroglu A, Alper F, Saglam L, et al. An epidemic of silicosis among former denim sandblasters. Eur Respir J. 2008 Nov;32(5):1295-303.

4. Ozdemir Doğan D, Ozdemir AK, Polat NT, Dal U, Gümüş C, et al. Prevalence of respiratory abnormalities and pneumoconiosis in dental laboratory technicians.Tuberk Toraks. 2010;58(2):135-41.

5. Mohemaiti P, Patigul N, Reshalaiti A, Honglamijiang AS. Characteristics of 3687 pneumoconiosis cases between 1985 and 2006 in Xinjiang Uyghur's Autonomous Region, China. Occup Environ Med. 2011 Nov;68(11):860. doi: 10.1136/oem.2009.047472.

6. Karaman Eyüboğlu C, Itil O, Gülşen A, Kargi A, Cimrin A. Dental technician's pneumoconiosis; a case report. Tuberk Toraks. 2008;56(2):204-9. (In Turkish.)

7. Tanrıverdi H, Altınsoy B, Uygur F, Erboy F, Yazgan Ö, Atalay F. A case of dental technician pneumoconiosis. Eur J Health Sci. 2015;1(2):76-78.

Received January 16, 2016 Accepted in revised form September 12, 2016 